\title{
microRNA 376a regulates follicle assembly by targeting Pcna in fetal and neonatal mouse ovaries
}

\author{
Huan Zhang ${ }^{1, *}$, Xiaohua Jiang ${ }^{1, *}$, Yuanwei Zhang ${ }^{1}$, Bo Xu ${ }^{1}$, Juan Hua ${ }^{1}$, Tieliang Ma ${ }^{1}$, Wei Zheng ${ }^{1}$, \\ Rui Sun ${ }^{1}$, Wei Shen ${ }^{2}$, Howard J Cooke ${ }^{1,3}$, Qiaomei Hao ${ }^{1}$, Jie Qiao ${ }^{4}$ and Qinghua Shi ${ }^{1}$ \\ ${ }^{1}$ Hefei National Laboratory for Physical Sciences at Microscale, School of Life Sciences, University of Science \\ and Technology of China, Hefei, Anhui 230027, People's Republic of China, ${ }^{2}$ Laboratory of Germ Cell Biology, \\ Key Laboratory of Animal Reproduction and Germplasm Enhancement in Universities of Shandong, Qingdao \\ Agricultural University, Qingdao, Shandong, China, ${ }^{3}$ MRC Human Genetics Unit, Institute of Genetics and \\ Molecular Medicine, University of Edinburgh, Edinburgh, UK and ${ }^{4}$ Department of Obstetrics and Gynecology, \\ Reproductive Medical Centre, Peking University Third Hospital, Beijing, China
}

Correspondence should be addressed to Q Shi; Email: qshi@ustc.edu.cn

*(H Zhang and X Jiang contributed equally to this work)

\begin{abstract}
In mammals, the primordial follicle pool, providing all oocytes available to a female throughout her reproductive life, is established perinatally. Dysregulation of primordial follicle assembly results in female reproductive diseases, such as premature ovarian insufficiency and infertility. Female mice lacking Dicer1 (Dicer), a gene required for biogenesis of microRNAs, show abnormal morphology of follicles and infertility. However, the contribution of individual microRNAs to primordial follicle assembly remains largely unknown. Here, we report that microRNA $376 a$ (miR-376a) regulates primordial follicle assembly by modulating the expression of proliferating cell nuclear antigen (PCna), a gene we previously reported to regulate primordial follicle assembly by regulating oocyte apoptosis in mouse ovaries. miR-376a was shown to be negatively correlated with Pcna mRNA expression in fetal and neonatal mouse ovaries and to directly bind to Pcna mRNA $3^{\prime}$ untranslated region. Cultured 18.5 days postcoitum mouse ovaries transfected with miR-376a exhibited decreased Pcna expression both in protein and mRNA levels. Moreover, miR-376a overexpression significantly increased primordial follicles and reduced apoptosis of oocytes, which was very similar to those in ovaries co-transfected with miR-376a and siRNAs targeting Pcna. Taken together, our results demonstrate that miR-376a regulates primordial follicle assembly by modulating the expression of Pcna. To our knowledge, this is the first microRNA-target mRNA pair that has been reported to regulate mammalian primordial follicle assembly and further our understanding of the regulation of primordial follicle assembly.
\end{abstract}

Reproduction (2014) 148 43-54

\section{Introduction}

Primordial follicles are composed of oocytes surrounded by several flattened granulosa cells, which are formed in fetal ovaries in humans and during the first few days after birth in rodents (Borum 1961, Baker 1963, Maheshwari \& Fowler 2008). Once formed, the primordial follicles serve as a finite source of developing follicles that decrease in size with age. The reproductive aging process of women is dictated by a gradual and steady decrease in the quantity and quality of oocytes held within the follicles. By the time of menopause, the number of primordial follicles falls below 1000 (Faddy et al. 1992, Faddy \& Gosden 1996, Broekmans et al. 2007). Thus, primordial follicle assembly is a critical process for female reproduction by determining the number of available oocytes. Disturbance of this process would lead to ovarian diseases, such as premature ovarian insufficiency and infertility (Sullivan \& Castrillon 2011).

Primordial follicle assembly occurs, when oocytes are individually surrounded by squamous pre-granulosa cells (Pepling \& Spradling 2001, Pepling 2006). Up to two thirds of the oocytes are lost before or shortly after birth (Pepling \& Spradling 2001, Pepling 2006). Apoptosis has been proposed to be the major mechanism underlying oocyte loss (Coucouvanis et al. 1993, Pesce \& De Felici 1994, De Pol et al. 1997, Pepling \& Spradling 2001, Lobascio et al. 2007, De Felici et al. 2008, Rodrigues et al. 2009). The deletion of the anti-apoptotic gene $B C l 2$ in mice reduces the number of both oocytes and primordial follicles at the sixth week postpartum but does not affect the number of primary and preantral follicles (Ratts et al. 1995, Flaws et al. 2001). On the contrary, targeted disruption of the apoptotic gene Casp2 
significantly increases the number of primordial follicles at 4 days postpartum (dpp; Bergeron et al. 1998).

We recently found that proliferating cell nuclear antigen (PCna), a key factor for DNA polymerase $\delta$ during DNA replication and repair, affects primordial follicle assembly by regulating oocyte apoptosis (Essers et al. 2005, Xu et al. 2011a). The expression of Pcna has been widely studied in ovaries of several arthropods and mammals (Oktay et al. 1995, Korfsmeier 2002, Muskhelishvili et al. 2005, Hutt et al. 2006, Balla et al. 2008, Picut et al. 2008, Zhang et al. 2010). For example, an increased Pcna expression during primordial follicle assembly has been observed in rats (Balla et al. 2008). The fluctuation of PCNA protein level was also observed during the development of fetal and neonatal mouse ovaries, with expression decreasing from 13.5 to 18.5 days postcoitum (dpc) and increasing from 18.5 dpc to $5 \mathrm{dpp}$ (Xu et al. 2011a). During primordial follicle assembly, most ovarian cells are in a quiescent state with oocytes arrested in diplotene stage and pre-granulosa cells arrested at the G0 stage (Robker \& Richards 1998). An earlier report showed that in quiescent cells, the level of Pcna is largely posttranscriptionally regulated (Chang et al. 1990). So this variation of Pcna expression we observed during ovarian primordial follicle assembly suggested that the level of this protein is highly regulated posttranscriptionally. microRNAs provide one possible posttranscriptional regulatory mechanism.

Over the past few years, microRNAs, small $(\sim 22$ nucleotides in length) non-coding RNA molecules, have emerged as a class of negatively regulatory factors that mainly regulate the turnover or translational efficiency of target mRNAs through base-pairing with their 3' untranslated region (UTR) (Bartel 2009, Huntzinger \& Izaurralde 2011). The small size of microRNAs, combined with their target recognition, provides microRNAs with the capacity and versatility to act as global gene regulators in a wide array of biological processes including cell proliferation and apoptosis (Bartel 2009, Krol et al. 2010, Huntzinger \& Izaurralde 2011). Many microRNAs are present in ovaries around the time of primordial follicle assembly in mammals (Choi et al. 2007, Ahn et al. 2010, Tripurani et al. 2010, Huang et al. 2011, Torley et al. 2011, Zhang et al. 2011, 2013). Female mice lacking Dicer 1 (Dicer), a gene required for the biogenesis of vast majority of microRNAs, show abnormal follicle morphology (Lei et al. 2010, Baley \& Li 2012). Thus, microRNAs probably play important roles during primordial follicle assembly. However, the contribution of individual microRNAs to primordial follicle assembly is largely unknown.

In this study, we found that miR-376a level was negatively correlated with that of Pcna mRNA in fetal and neonatal mouse ovaries. miR-376a has been demonstrated to directly bind to the $3^{\prime}$ UTR of PCna mRNA. Transfection of miR-376a mimics into cultured ovaries at $18.5 \mathrm{dpc}$ increased primordial follicle assembly by decreasing oocyte apoptosis via suppressing
Pcna mRNA and protein expression. Our results indicate that miR-376a is a novel regulator of primordial follicle assembly that regulates oocyte apoptosis by modulating the expression of Pcna.

\section{Materials and methods}

\begin{abstract}
Animals
ICR mice were purchased from the National Rodent Laboratory Animal Center (Shanghai Branch, China) and housed under controlled photoperiod conditions (lights on 0800-2000 h) and were supplied with food and tap water ad libitum. All animal studies were conducted in accordance with the Institutional Animal Care and Use Committee of University of Science and Technology of China. Fetal or neonatal mouse ovaries were obtained from the pregnant mice between $13.5 \mathrm{dpc}$ and $5 \mathrm{dpp}$. The presence of a copulation plug in the noon after mating was designated as $0.5 \mathrm{dpc}$.
\end{abstract}

\section{RNAi on cultured fetal mouse ovaries}

The ovaries from $18.5 \mathrm{dpc}$ mice were cultured as described (Shen et al. 2007). Fetal ovary RNAi was initiated as described (Wang \& Roy 2006). Briefly, cultured ovaries were transfected with $200 \mathrm{nM}$ siRNAs (Invitrogen) using Metafectene (Biontex, T020-1.0, Munich, Germany) following the supplier's instructions. Half of the medium was changed at the 48th hour after RNAi initiation with complete medium without siRNAs.

The sequence of Pcna siRNAs is 5'-GGCATTGCTAGAAATTGAGAA-3', targeting 930-950 nt of PCna mRNA (Paddison et al. 2004), and the non-targeting control siRNA sequence is 5'-TTCTCCGAACGTGTCACG-3' which has no homology to any known mouse mRNAs. All data were obtained from didymous ovaries (for two ovaries of a mouse, one was transfected with target siRNAs and the other with non-targeting control siRNAs).

\section{Transfection of microRNA mimics}

microRNA mimics are chemically synthesized, doublestranded RNAs that mimic mature endogenous microRNAs after transfection into cells. For the microRNA overexpression in vitro, cultured ovaries were transfected with microRNA mimics (200 nM, Genepharma, Shanghai, China). These microRNA mimics were delivered using Metafectene (Biontex) according to the manufacturer's protocol. Forty-eight hours after transfection, the medium was changed with replacement of half of the complete medium. Ovaries were harvested $96 \mathrm{~h}$ after transfection. All data were obtained from didymous ovaries (one ovary was transfected with microRNA mimics and the other with non-targeting siRNAs, which are random double-stranded sequence molecules that can mimic microRNAs and were validated not to produce identifiable effects on known microRNA function, as control).

\section{Immunofluorescence and western blot assay}

Immunohistochemistry and western blot assays were performed as described previously (Xu et al. 2011a). 


\section{Construction of luciferase reporter vectors}

The sequence encoding the mouse Pcna mRNA 3' UTR that contains the putative miR-376a binding site was amplified by PCR using the following two primers: forward primer 5'-GCTCTCTCGAGGCATTGCTAGAAATTGAGAAAACT-3' and reverse primer 5'-GTCGAGCGGCCGCTGACTTTTCAAATTGTTAACTTTA-3'. These two primers contain Xhol or Notl recognition sites at their $5^{\prime}$ end. The sequence encoding the mutant PCna mRNA 3' UTR that lacks the putative miR-376a binding ability was synthesized by PCR according to the published method (Higuchi et al. 1988). For mutation of the putative binding site (243-263 bp from the start of the 3' UTR), the following pair of primers was employed in addition to the pair of primers used for amplification of WT $3^{\prime}$ UTR: 5'-GCTTTACAAATACTGGTGATTTTCATCATGCTTCTTGACG-3' and 5'-CGTCAAGAAGCATGATGAAAATCACCAGTATTTGTAAAGC- $3^{\prime}$. These PCR products were digested with Xhol and Notl and cloned into the psiCHECK-2 luciferase reporter vector (Promega) at the corresponding restriction sites. The sequences of inserted fragments were verified by sequencing.

\section{Luciferase assay}

HEK 293T cell was transfected using Lipofectamine 2000 (Invitrogen, 11668) according to the manufacturer's instructions. In short, $10^{5}$ cells were plated in a 24 -well tissue culture plate the day before transfection. The luciferase reporter constructs $(100 \mathrm{ng})$, together with miR-376a mimics (50 nM) (GenePharma) were incubated with $1.5 \mu$ l Lipofectamine 2000 and transfected into cells. After $6 \mathrm{~h}$, the transfection solution was replaced with fresh medium. Cell lysates were produced $24 \mathrm{~h}$ after transfection and assayed using the Dual-Luciferase Reporter Assay System (Promega, E1910) following the manufacturer's instructions. The Renilla luciferase activity was normalized to that of the firefly luciferase.

\section{Cell proliferation and apoptosis analysis}

To assess cell proliferation, transfected mouse ovaries were cultured in medium with $100 \mathrm{nM}$ bromodeoxyuridine (BrdU) (Sigma, B9285) added $24 \mathrm{~h}$ before ovary harvesting. The ovaries were fixed and embedded in paraffin and sectioned. BrdU-labeled cells in the sections were detected immunohistochemically using a mouse anti-BrdU MAB (NeoMarkers, MS-1058-P0, Fremont, CA, USA; 1:200) and imaged using a BX61 Olympus fluorescence microscope. Apoptotic cells were detected in sections by TUNEL assay according to the manufacturer's specifications. Ovarian sections were imaged and TUNEL assay-positive cells were counted manually using Image-Pro plus Software (Media Cybernetics, Rockville, MD, USA).

\section{Real-time PCR for mRNAs}

RNA isolation, RT-PCR, and real-time PCR were performed as described previously (Xu et al. 2011a). All PCR primers used were listed in Supplementary Table 1, see section on supplementary data given at the end of this article. For realtime PCR analyses, CT values of samples were normalized to the corresponding CT values of Gapdh. Quantification of the fold change in gene expression was determined by the comparative $C T$ method.

\section{Real-time PCR for microRNAs}

For quantitative PCR analysis of microRNAs, pooled tissues or transfected ovaries were collected and total RNAs were extracted using TRIzol reagents (Invitrogen). For detecting and quantifying the expression of specific microRNAs, $1 \mu \mathrm{g}$ RNA was reverse transcribed using RT Kit (ABI, 4366596, Carlsbad, CA, USA) with preformulated primers (ABI). Probe sets $(\mathrm{ABI})$ were designed to perform real-time PCR amplification with products from $\mathrm{RT}$ reaction using TaqMan Universal PCR Master Mix (ABI, 4324018). For real-time PCR analyses, $C T$ values of samples were normalized to the corresponding $C T$ values of U6. Quantification of the fold change in microRNA expression was determined by the comparative CT method.

\section{Locked nucleic acid in situ hybridization}

Locked nucleic acid in situ hybridization (LNA-ISH) was performed on paraffin sections using LNA probes for miR-376a (Exiqon, Woburn, MA, USA). Ovaries were fixed in $10 \%$ formaldehyde for $20 \mathrm{~min}$ before paraffin embedding and $4 \mu \mathrm{m}$-thick paraffin sections were attached to microscope slides. Paraffin sections were incubated at $60^{\circ} \mathrm{C}$ for $1 \mathrm{~h}$. Following de-paraffinization in xylene, sections were re-hydrated in a series of graded ethanol/water solutions. After incubation in acetylation solution (acetic anhydride (Sigma, 320102; 0.25\%) and triethanolamine (Sigma, T1377; $1.33 \%)$ ) for $15 \mathrm{~min}$, the slides were digested in proteinase $\mathrm{K}$ (Promega, V3021; 1:500) for 20 min and subsequently washed in PBS. Following rinse in PBS, the slides were de-hydrated in a series of graded ethanol/water solutions and incubated with hybridization buffer containing the digoxigenin-labeled LNA probe in an oven at $56{ }^{\circ} \mathrm{C}$ overnight. After washed with $5 \times$ SSC (saline-sodium citrate buffer) twice, $1 \times$ SSC twice, and $0.2 \times$ SSC twice, $15 \mathrm{~min}$ each at $55^{\circ} \mathrm{C}$, the slides were blocked with blocking buffer for $20 \mathrm{~min}$ and incubated with anti-digoxigenin Fab fragment (Roche, 11214667001; 1:500) overnight at $4{ }^{\circ} \mathrm{C}$ in a humid chamber. The visualization was performed using BCIP/NBT Liquid Substrate System (Sigma, B1911) in the dark. After stringent washes, the slides were mounted with coverslips using vectashield mounting medium.

\section{Morphometric evaluation of oogenesis and folliculogenesis}

To identify oocytes and follicles, ovarian sections were immunohistochemically labeled with an antibody-recognized $\mathrm{MVH}$, a protein specifically expressed in germ cells (Fujiwara et al. 1994) and Hoechst 33342 for nuclei of ovarian cells. The sections were analyzed using an Olympus fluorescence microscope (BX61). All cells labeled by $\mathrm{MVH}$ antibodies (oocytes) were counted. Based on their localization, oocytes were designated as in primordial or primary follicles according to the previous reports (Meredith et al. 2000, Pepling \& Spradling 2001). 


\section{Statistical analysis}

For each ovary, oocytes or follicles were counted as previously reported (Chen et al. 2007, Nilsson et al. 2007, Reddy et al. 2008, Xu et al. 2011a, Kim et al. 2013). For real-time PCR and western blot analysis, two or three cultured ovaries per group were pooled to form one sample and repeated at least three times for statistical analysis. Student's $t$-test was used to compare means between two independent samples in real-time PCR analysis. In other statistical analyses, Tukey's multiple comparison test was used to compare means among multiple groups.

\section{Results \\ miR-376a is negatively correlated with Pcna mRNA level in mouse ovaries in vivo during follicle assembly and can bind to the $3^{\prime}$ UTR of Pcna mRNA directly}

To find microRNAs that may regulate mouse Pcna expression, the local package of miRanda v3.3a was used to predict the microRNAs that may target PCna mRNA based on its $3^{\prime}$ UTR (Betel et al. 2008). The parameters used for the prediction process were listed in Supplementary Table 2, see section on supplementary data given at the end of this article. According to miRanda results, PCna was potential target of 163 microRNAs (Supplementary Table 3). Among these microRNAs, 37 microRNAs were detected by our microarray chip assay in mouse ovaries during follicle assembly, and when 1.5-fold change in microRNA abundance was considered, only three microRNAs remained, of which only one microRNA, miR-376a, exhibited a negative correlation with Pcna mRNA level (H Zhang, X Jiang, Y Zhang, B Xu, J Hua, W Zheng and $R$ Sun, unpublished data). To confirm the relationship between miR-376a and Pcna mRNA expression, the level of miR-376a and Pcna mRNA was measured in fetal and neonatal mouse ovaries by real-time PCR (Fig. 1A). miR-376a levels slightly increased from 13.5 to $16.5 \mathrm{dpc}$, then decreased, and reached a minimum in 3 dpp ovaries and increased again thereafter. miR-376a was also found to express very differently in various tissues, with much higher expression in ovary and testis of newborn and brain of adult mice than in other tissues (Fig. 1B). Furthermore, microRNA ISH experiments demonstrated that miR-376a was localized in cytoplasm of some oocytes in cysts at $16.5 \mathrm{dpc}$. At $1 \mathrm{dpp}$, miR-376a was mainly localized in cytoplasm of oocytes and granulosa cells in primordial follicles (Fig. 1C). This expression pattern in the developing ovaries and tissue specificity are consistent with a regulatory role of miR-376a in fetal and neonatal mouse ovaries.

To determine whether miR-376a can directly bind to the $3^{\prime}$ UTR of Pcna mRNA, a dual-luciferase reporter system was used as previously reported (Grentzmann et al. 1998). We constructed dual-luciferase reporter vectors by inserting the DNA sequence encoding the WT or mutant (which cannot bind miR-376a) 3' UTR of PCna
mRNA downstream the Renilla luciferase gene (Fig. 1D) and transfected them with miR-376a mimics into 293T cells respectively. A significant decrease in relative luciferase activity was observed in cells co-transfected with the WT constructs and miR-376a mimics, but not in cells co-transfected with the mutant constructs and miR-376a mimics (Fig. 1E). These results demonstrate that miR-376a can directly bind to the $3^{\prime}$ UTR of mouse Pcna mRNA.

\section{miR-376a negatively regulates Pcna expression in cultured mouse ovaries}

To determine whether miR-376a can regulate Pcna expression in cultured ovaries, we transfected miR-376a mimics into cultured $18.5 \mathrm{dpc}$ mouse ovaries and measured Pcna mRNA and protein levels $96 \mathrm{~h}$ after transfection. An $\sim 20$-fold increase in miR-376a level was observed in ovaries transfected with miR-376a mimics for $96 \mathrm{~h}$, compared with those in control ovaries (Fig. 2A). This indicates a high efficiency of microRNA transfection in our fetal mouse ovary culture system. Of note, PCNA protein level as well as mRNA level was greatly decreased in ovaries transfected with miR-376a mimics, Pcna siRNAs or both together compared with controls (Fig. 2B, C and $D$ ). These results indicate that miR-376a is able to downregulate Pcna expression in cultured mouse ovaries.

\section{miR-376a increases primordial follicle assembly by promoting oocyte survival around primordial follicle formation via downregulating Pcna expression}

The effects of miR-376a on primordial follicle assembly in cultured ovaries were determined in cultured ovaries $96 \mathrm{~h}$ after transfection of miR-376a mimics or controls at 18.5 dpc (Fig. 3A). miR-376a mimic-transfected ovaries exhibited more primordial follicles than the controls; similar results were observed in ovaries transfected with PCna siRNAs (Fig. 3A and B and Supplementary Fig. 1, see section on supplementary data given at the end of this article). To be noted, in the control group, there were fewer primordial follicles, in which oocytes were larger than those in miR-376a mimic-transfected ovaries, as reported in Pcna siRNA transfected ovaries (Xu et al. 2011a). We prolonged the culture to 6 days and found that there were still more primordial follicles in miR-376a mimic-transfected ovaries; however, the difference in the developing follicle index (the ratio of developing follicles:total follicles) between experimental and control ovaries decreased (Supplementary Fig. 2). We also employed miR-376a inhibitors in cultured ovaries; however, they had no obvious effect on primordial follicle assembly (Supplementary Fig. 3). To show whether the increase in primordial follicles in miR-376a mimictransfected ovaries is caused by downregulation of Pcna expression, we co-transfected miR-376a mimics and PCna siRNAs into $18.5 \mathrm{dpc}$ ovaries and analyzed the 

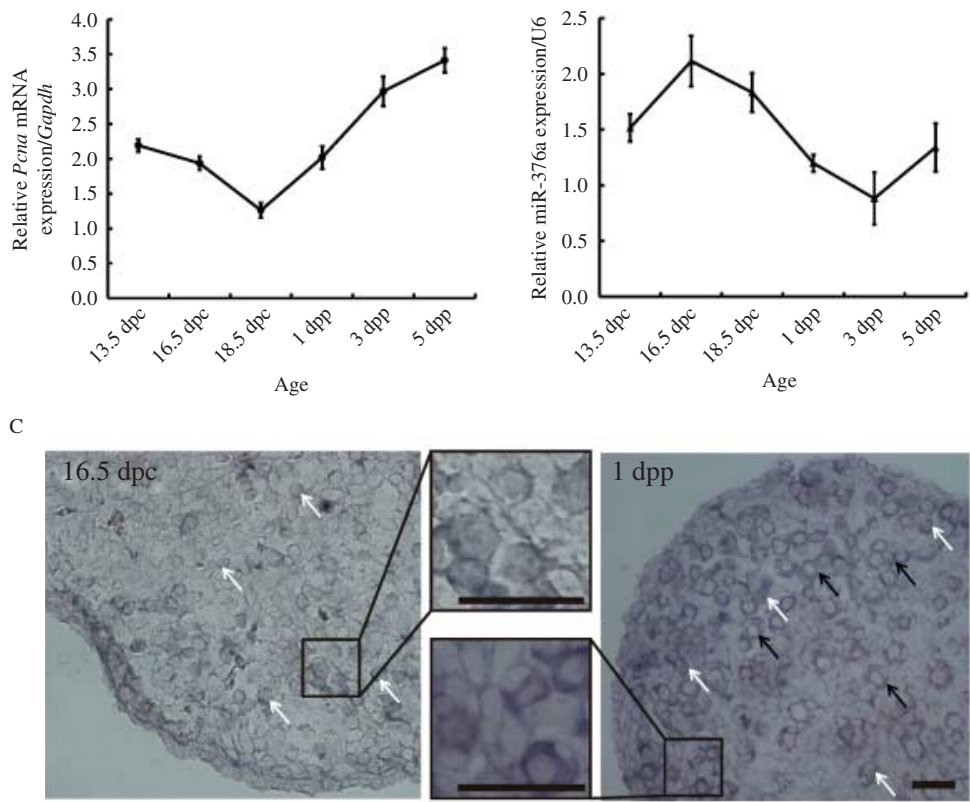

3'- TGCACCTAAAAGGAGATGCTA-5' miR-376a ! | |l||||| || |ill|

5'- ...TGGTGATTTTCATCAATGAT...- 3' Mouse Pcna-3' UTR putative miR-376a binding site (243-263 bp)

5'-...TGGTGATTTTCATCA $\lceil G C T$ T...- 3' Mutant binding site
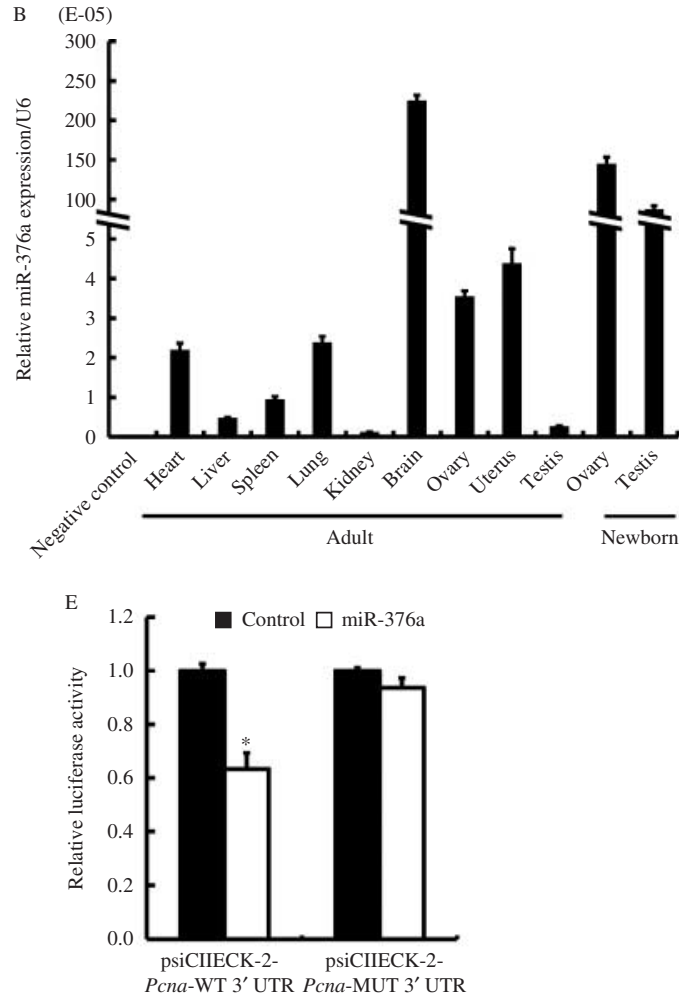
Pcna-WT 3'UTR Pcna-MUT 3' UTR

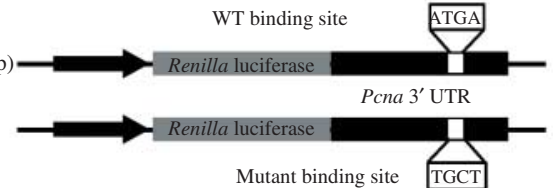

Figure 1 Expression and localization of miR-376a in fetal/neonatal ovaries and the direct binding of miR-376a to PCna mRNA 3' UTR. (A) miR-376a and PCna mRNA levels were detected by real-time PCR in fetal and neonatal mouse ovaries respectively. U6 and Gapdh were used as internal control respectively. Data are presented as mean \pm S.E.M. $(n=3)$. (B) miR-376a expression in various mouse organs, detected by real-time PCR, normalized to U6 expression. Negative control, no template control. Data are presented as mean \pm s.E.M. $(n=3)$. (C) Expression and localization of miR-376a in fetal/neonatal mouse ovaries detected by in situ hybridization. White arrows, miR-376a-positive oocytes. Black arrows, miR-376apositive somatic cells. Bar: $25 \mu \mathrm{m}$. (D) Mature miR-376a sequence and its putative binding site in the 3' UTR of mouse Pcna mRNA. Dual-luciferase reporter constructs contain a DNA sequence encoding WT or mutant PCna mRNA 3' UTR, which is or is not able to bind miR-376a respectively. (E) Relative luciferase activity is measured $24 \mathrm{~h}$ after co-transfection of each of the constructs together with miR-376a mimics (50 nM) or controls in 293T cells. Data are presented as mean \pm s.E.M. $(n=3)$. Differences between groups were considered significant when the Student's $t$-test gave a $P$ value $<0.05(*)$.

primordial follicles $96 \mathrm{~h}$ after transfection. Indeed, results observed in ovaries after co-transfection were very similar to those in ovaries transfected with either miR-376a mimics or Pcna siRNAs alone (Fig. $3 \mathrm{~A}$ and $\mathrm{B}$ and Supplementary Fig. 1). These results together with those mentioned earlier indicate that both miR-376a and PCna siRNAs are functioning in the same pathway to regulate primordial follicle formation.

Increased primordial follicle number in neonatal mouse ovaries has been attributed to the increased number of surviving oocytes during follicle formation (Meredith et al. 2000). To understand whether the increased primordial follicles in miR-376a-transfected ovaries result from more surviving oocytes, we counted the oocytes in cultured ovaries every $24 \mathrm{~h}$ after miR-376a mimics transfection in $18.5 \mathrm{dpc}$ ovaries (Fig. 3C).
Ovaries transfected with miR-376a mimics exhibited more oocytes at 72 and $96 \mathrm{~h}$ after transfection than the control ovaries (Fig. 3D). Similar results were observed in ovaries transfected with Pcna siRNAs, and importantly in those co-transfected with Pcna siRNAs and miR-376a mimics (Fig. 3D). These results indicate that transfection of miR-376a in mouse ovaries around the time of primordial follicle assembly causes the increase of surviving oocytes by decreasing the Pcna expression.

\section{miR-376a overexpression reduces oocyte apoptosis in fetal mouse ovaries around primordial follicle assembly by suppression of Pcna expression}

It has been established that Pcna promotes apoptosis of oocytes during primordial follicle assembly (Xu et al. 2011a). 

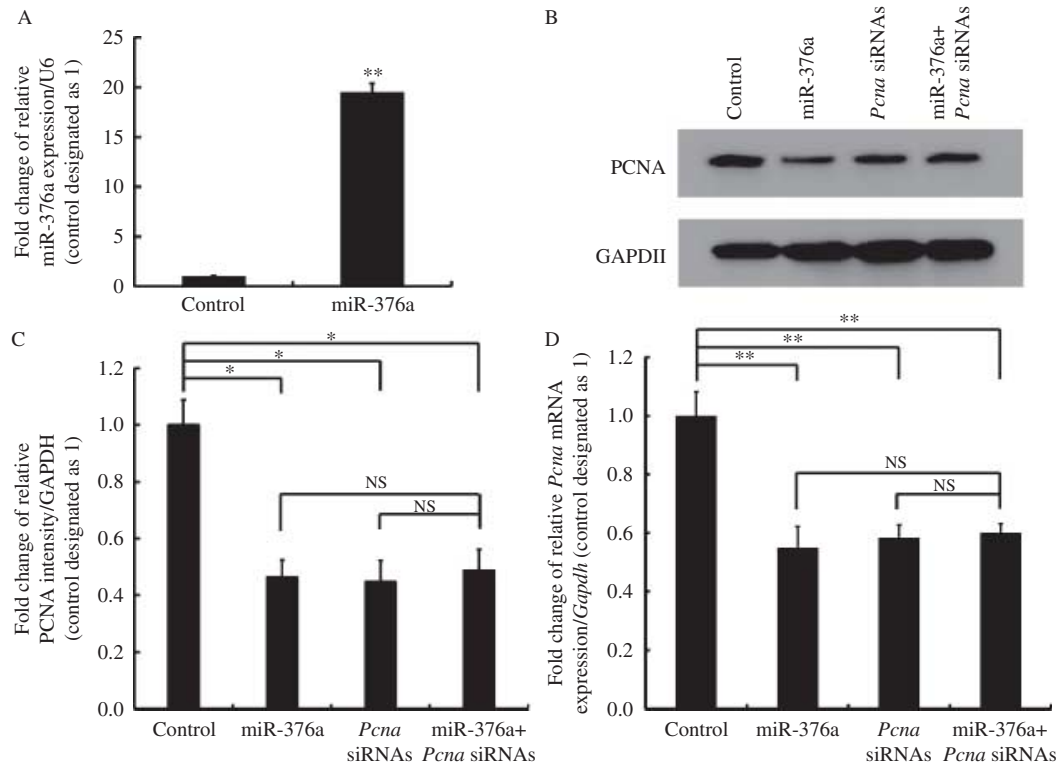

Figure 2 miR-376a overexpression downregulates PCna expression in fetal mouse ovaries. (A) The overexpression efficiency of miR-376a in cultured fetal mouse ovaries was determined by real-time PCR $96 \mathrm{~h}$ after transfection. The expression of miR-376a was normalized to U6. The relative miR376 a expression in control ovaries was designated as 1 . Data are presented as mean \pm s.E.M. $(n=3)$. Differences between groups were considered highly significant when the Student's $t$-test gave a $P$ value $<0.01(* *)$. (B) PCNA protein levels in fetal mouse ovaries transfected with miR-376a mimics, PCna siRNAs, both together or non-targeting microRNA mimics (Control) for $96 \mathrm{~h}$ were measured by western blot assays. GAPDH were used as an internal control. (C) Relative intensity of PCNA to GAPDH of the western blot bands. The data of control ovaries was designated as 1 . Data are presented as mean \pm S.E.M. $(n=3-9)$. Differences among groups were considered significant when the Tukey's multiple comparison test gave a $P$ value $<0.05\left(^{*}\right)$. (D) Relative Pcna mRNA expression levels in fetal mouse ovaries transfected with miR-376a mimics, Pcna siRNAs, both together or non-targeting microRNA mimics (control) for $96 \mathrm{~h}$ were detected by real-time PCR. The relative Pcna mRNA expression in control ovaries was designated as 1. Data are presented as mean \pm S.E.M. $(n=3-9)$. Differences among groups were considered significant when the Tukey's multiple comparison test gave a $P$ value $<0.05$. ${ }^{*} P<0.05$ and ${ }^{* *} P<0.01$.

To investigate whether the increased oocytes in ovaries caused by miR-376a transfection result from the decreased oocyte apoptosis mediated by downregulation of Pcna expression, TUNEL assays were performed on ovaries transfected with miR-376a mimics. The results showed that miR-376a mimics transfection apparently inhibited oocyte apoptosis (Fig. 4A) and statistical analysis revealed that the number of apoptotic oocytes in ovaries transfected with miR-376a mimics was significantly lower than in the controls (Fig. 4B). Additionally, we measured the expression levels of some genes that related to apoptosis and oocyte survival. mRNA levels significantly decreased for proapoptotic genes such as Bax, Tnf, and Tnfrsf1b (Tnfr2), increased for anti-apoptotic gene $B C l 2$ and oocyte survival genes Pard6a (Par6), Lhx8 in ovaries transfected with miR-376a, compared with the controls (Fig. 4C). Altogether, these results indicate that miR-376a is able to reduce oocyte apoptosis in fetal mouse ovaries during primordial follicle assembly.

A similar decrease in the number of apoptotic oocytes was observed in ovaries transfected with PCna siRNAs, co-transfection of Pcna siRNAs and miR-376a mimics did not further decrease the number of apoptotic oocytes (Fig. 4A and B). This indicates that transfection of miR-376a decreases oocyte apoptosis by suppression of Pcna expression.

\section{Overexpression of miR-376a slightly decreases somatic cell proliferation in mouse ovaries around primordial follicle assembly mediated by repression of Pcna expression}

To determine whether miR-376a transfection induces a slight decrease in somatic cell proliferation as does Pcna siRNA transfection (Xu et al. 2011a), we measured cell proliferation in miR-376a mimic-transfected ovaries using BrdU incorporation as a marker of cell proliferation (Johnson et al. 2004). We counted the number of BrdU-positive somatic cells in ovaries every $24 \mathrm{~h}$ after transfection initiation (Fig. 5A and B). During the first $72 \mathrm{~h}$ when primordial follicles were formed actively, miR-376a mimic-transfected ovaries showed a slight but not significant decrease in the number of BrdU-positive somatic cells, when compared with the controls. From 72 to $96 \mathrm{~h}$ after transfection, the number of BrdUpositive cells increased apparently when compared with that in the first $72 \mathrm{~h}$ in miR-376a mimic-transfected ovaries. The BrdU-positive cells mainly localized in the area where the primordial follicle assembly was not active (Fig. 5A). A similar increase in somatic cell proliferation was observed in ovaries transfected with Pcna siRNAs, and co-transfection of Pcna siRNAs and miR-376a mimics did not further the influence on 


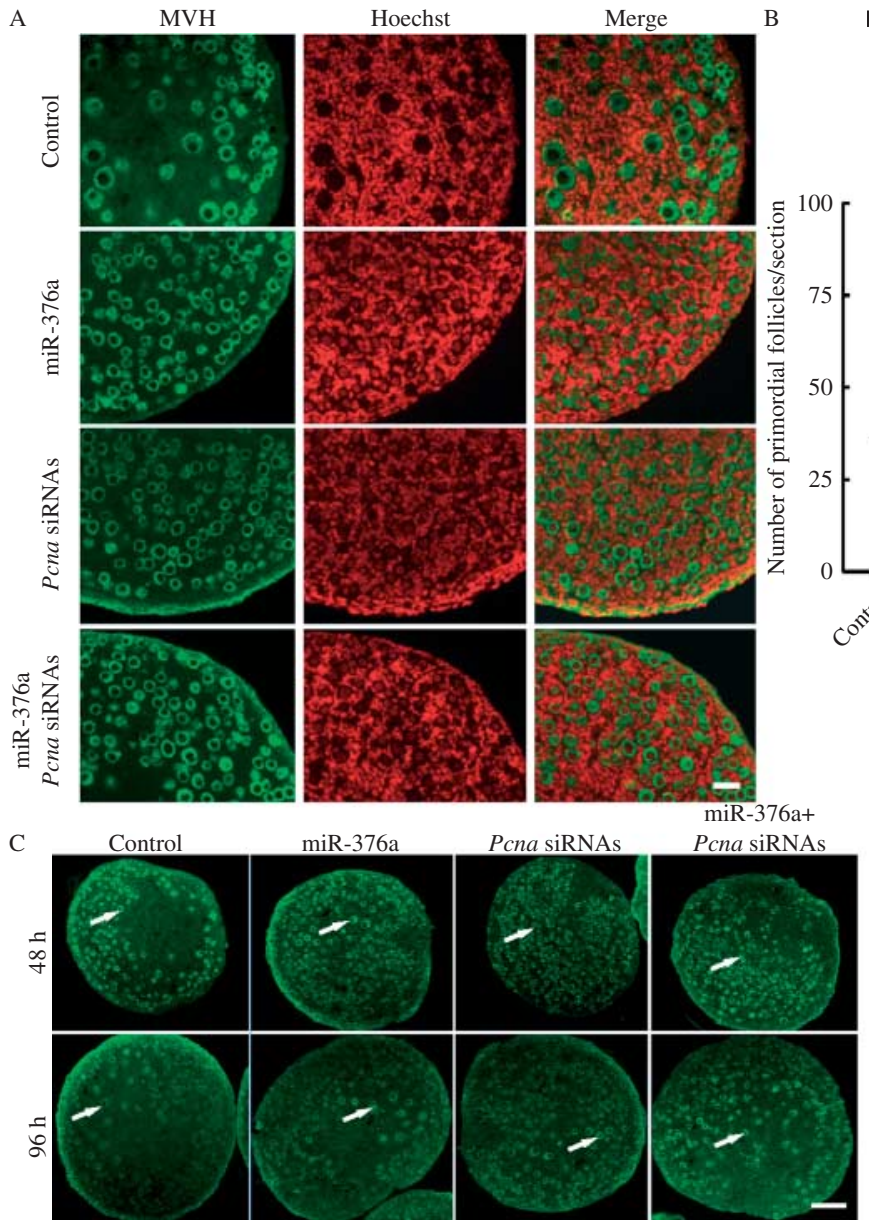

Primordial follicles
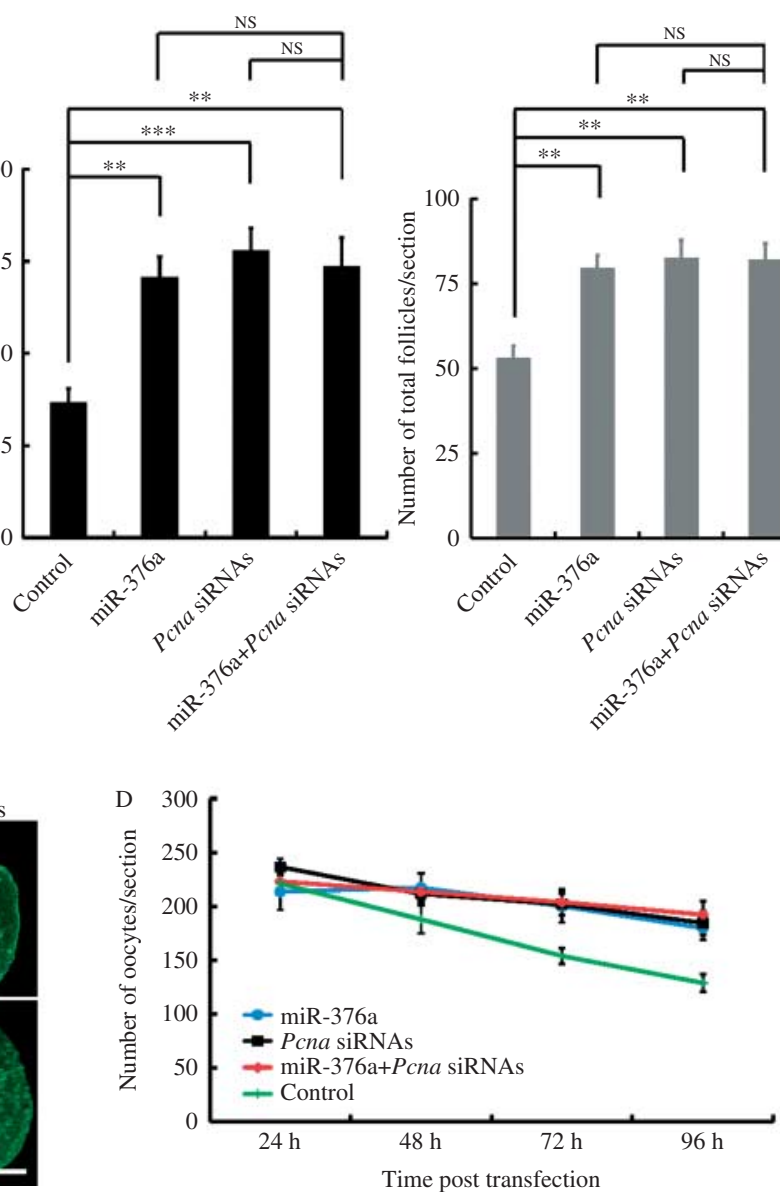

Figure 3 miR-376a promotes primordial follicle assembly and oocyte survival by downregulating Pcna expression. (A) Follicles were detected immunohistochemically in sections of mouse ovaries $96 \mathrm{~h}$ after transfection with miR-376a mimics, Pcna siRNAs or both together. Ovaries transfected with non-targeting siRNAs are used as controls. MVH is a protein specifically expressed in germ cell cytoplasm. Bar: $25 \mu \mathrm{m}$. (B) Quantification of primordial and total follicles in the transfected and control ovaries. Each bar represents a mean \pm s.E.M. of results from 16 ovaries from different animals of five independent experiments. Differences among groups were considered significant when the Tukey's multiple comparison test gave a $P$ value $<0.05$. ${ }^{* *} P<0.01$, and ${ }^{* * *} P<0.001$. (C) Oocytes (arrow) were immunohistochemically detected in sections of ovaries every $24 \mathrm{~h}$ after transfection of $18.5 \mathrm{dpc}$ fetal mouse ovaries with miR-376a mimics, Pcna siRNAs, or both together. Ovaries transfected with non-targeting siRNAs are used as the control. Oocytes are labeled with MVH antibodies (green). Bar: $100 \mu \mathrm{m}$. (D) Quantification of oocytes in the ovaries every $24 \mathrm{~h}$ after transfection of $18.5 \mathrm{dpc}$ fetal mouse ovaries with miR-376a mimics, Pcna siRNAs, both together, or non-targeting siRNAs (control). Data are presented as mean \pm s.E.M. $(n=5)$.

somatic cell proliferation (Fig. 5A and B). Taken together, overexpression of miR-376a during primordial follicle assembly slightly decreases somatic cell proliferation that is not involved in primordial follicle formation.

\section{Discussion}

Previous reports have shown that female reproductive system-specific Dicer1 conditional knockout or Dicer1 general hypomorphic mutated mice are infertile due to the interruption of overall microRNA production (Murchison et al. 2007, Otsuka et al. 2008, Lei et al. 2010). Most recently, microRNA expression profiles have been established in ovaries in human (Zhang et al. 2011), mice (Choi et al. 2007, Ro et al. 2007,
Ahn et al. 2010, Zhang et al. 2013), and cattle (Tripurani et al. 2010, Huang et al. 2011) around the time of primordial follicle assembly. All these studies suggested important roles of microRNAs in the developing ovaries. However, little is known about the exact function of individual microRNAs and their targets in primordial follicle formation. Here, we found that during primordial follicle assembly, miR-376a can repress the expression of Pcna through directly binding to Pcna mRNA 3' UTR. Overexpression of miR-376a results in more oocytes and primordial follicles in cultured mouse ovaries around primordial follicle assembly by reducing oocyte apoptosis through down-regulation of Pcna expression. This study demonstrates that miR-376a is a novel regulator of primordial follicle assembly in mouse. 


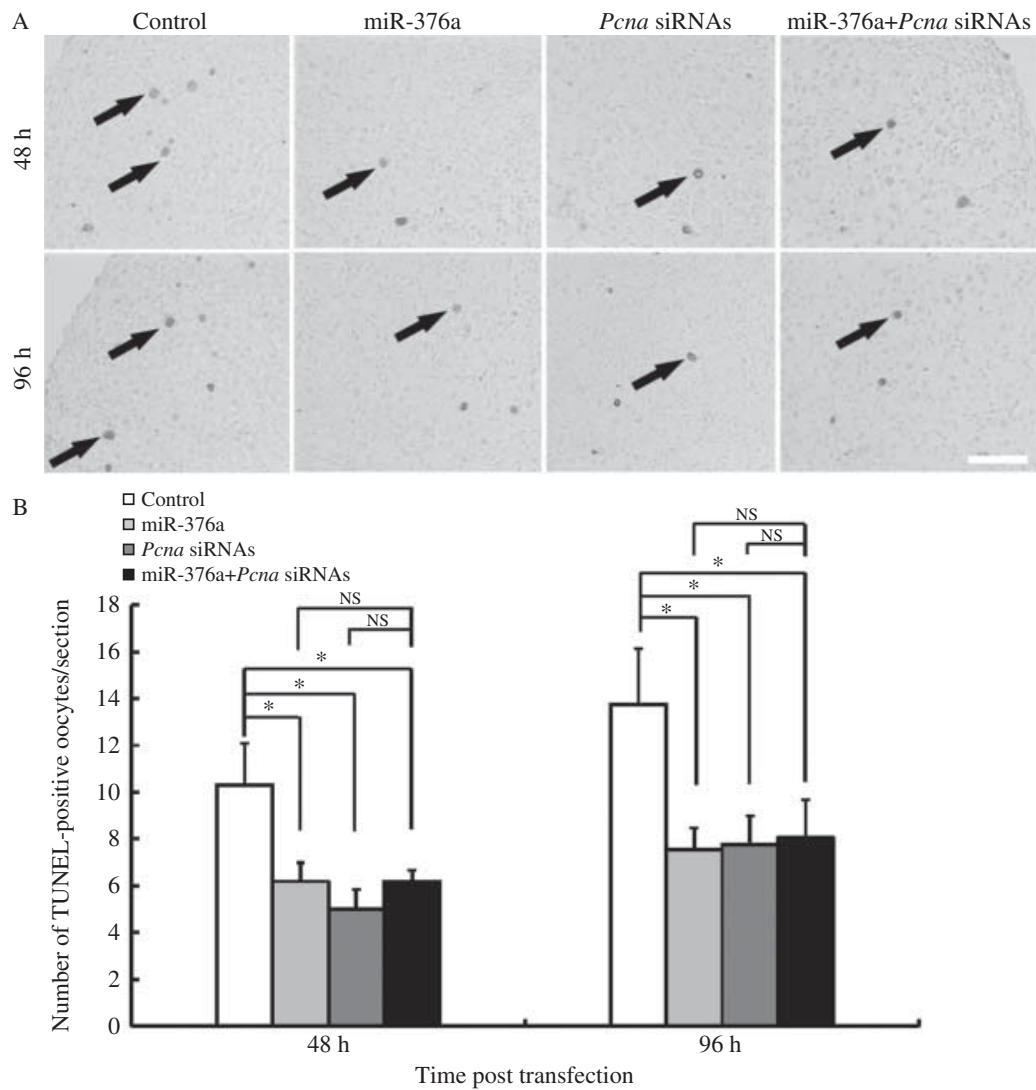

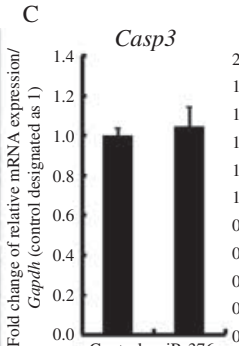
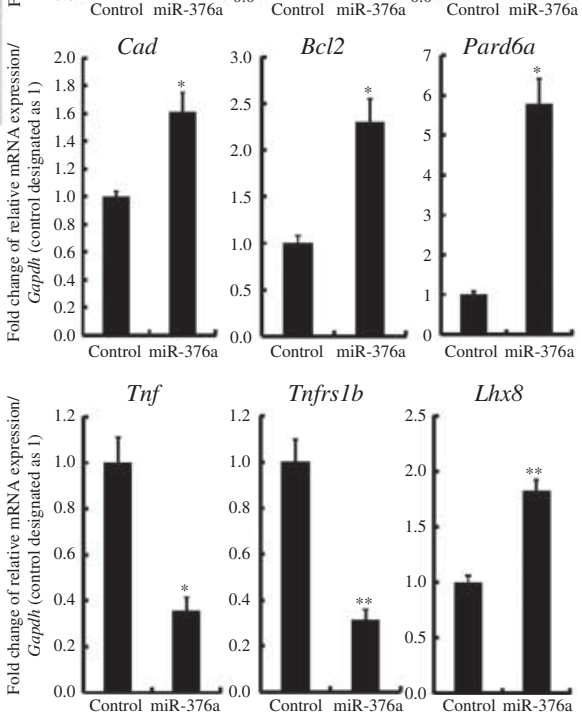

Tnfrs $1 b$

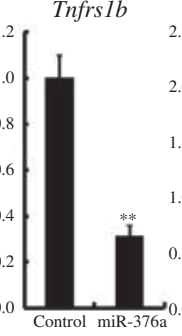

Lhx

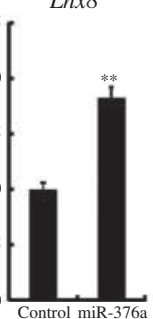

Figure 4 miR-376a alleviates the apoptosis of oocytes in fetal mouse ovaries by downregulating Pcna expression. (A) Apoptotic oocytes (arrow) were detected using TUNEL assay 48 and $96 \mathrm{~h}$ after transfection of $18.5 \mathrm{dpc}$ fetal mouse ovaries with miR-376a mimics, PCna siRNAs, or both together. Ovaries transfected with non-targeting siRNAs are used as controls. Bar: $100 \mu \mathrm{m}$. (B) Quantification of TUNEL-positive oocytes in ovaries transfected with miR-376a mimics, Pcna siRNAs, both together, or non-targeting siRNAs (control). Data are presented as mean \pm s.E.M. ( $n=3-9$ ). Differences among groups were considered significant when the Tukey's multiple comparison test gave a $P$ value $<0.05\left({ }^{*}\right)$. (C) The mRNA expression of apoptosis- and oocytes' survival-related genes in $18.5 \mathrm{dpc}$ fetal mouse ovaries transfected with miR-376a mimics or controls for $96 \mathrm{~h}$ was analyzed by real-time PCR. The relative expression was normalized to Gapdh. The relative mRNA expression levels in control ovaries were designated as 1. Data are presented as mean \pm S.E.M. $(n=3)$. Differences between groups were considered significant or highly significant when the Student's $t$-test gave a $P$ value $<0.05\left(^{*}\right)$ or $P$ value $<0.01\left({ }^{* *}\right)$.

The distinct expression profile of Pcna during the ovary development was found in fetal and newborn rats, with PCNA-positive oocytes observed decreasing after birth and increasing when primordial follicles start to assembly (Balla et al. 2008). In mice, during early ovary development, a fluctuant expression pattern was observed, i.e. decreasing expression from $13.5 \mathrm{dpc}$ to $18.5 \mathrm{dpc}$ and increasing expression from $18.5 \mathrm{dpc}$ to $5 \mathrm{dpp}$ (Xu et al. 2011a). The variable Pcna expression before and during primordial follicle assembly has also been detected by others in mice and rats (Muskhelishvili et al. 2005, Kerr et al. 2006). All these results indicate that the temporal expression of Pcna during primordial follicle assembly is tightly regulated. microRNAs have been shown to function as negative regulators of many genes during ovary development (Carletti et al. 2010, Xu et al. 2011b). The regulation of PCna expression by microRNAs has been mentioned in several studies (Han et al. 2010, Sirotkin et al. 2010, Raschzok et al. 2011). For example, downregulation of Dicer1 was associated with enhanced expression of Pcna in human cancer cell lines (Han et al. 2010), and a total of 53 microRNAs were shown to most likely repress the expression of Pcna in cultured human granulosa cells (Sirotkin et al. 2010). However, these studies did not determine whether the Pcna expression is directly regulated by microRNAs because Pcna expression was always used as a cell proliferation marker in these reports and changes in its expression level might also be the accompanying effect of microRNAs on cell proliferation.

According to miRanda prediction (Betel et al. 2008), there is a putative binding site of miR-376a in Pcna 3' UTR (Fig. 1D). Dual-luciferase activity assay confirmed that miR-376a could directly bind to PCna 3' UTR (Fig. 1E). We also found that over-expression of miR$376 \mathrm{a}$ in cultured $18.5 \mathrm{dpc}$ ovaries could down-regulate PCNA protein and mRNA levels (Fig. 2B, C and D). The decrease in PCNA protein abundance in ovaries transfected with miR-376a may be a consequence of reducing Pcna mRNA abundance or a combination 


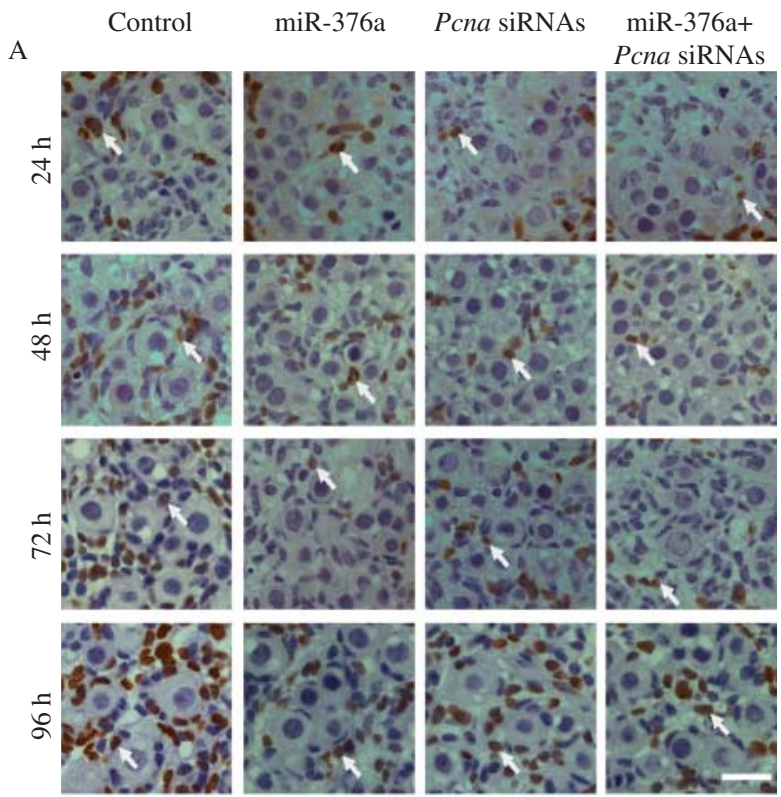

B

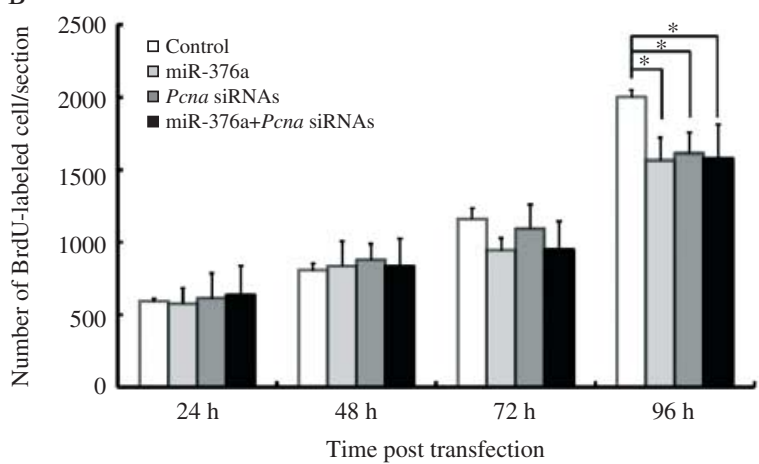

Figure 5 miR-376a slightly decreases somatic cell proliferation in fetal mouse ovaries by downregulating PCna expression. (A) Proliferation of somatic cells were determined by BrdU-labeling assay in cultured ovaries every $24 \mathrm{~h}$ after transfection with miR-376a mimics, PCna siRNAs, both together, or non-targeting siRNAs (control). Arrows, BrdU-positive somatic cells. Bar: $25 \mu \mathrm{m}$. (B) Quantification of BrdUpositive cells in ovaries transfected with miR-376a mimics, Pcna siRNAs, both together, or non-targeting siRNAs (control). Data are presented as mean \pm s.E.M. $(n=3-9)$. Differences among groups were considered significant when the Tukey's multiple comparison test gave a $P$ value $<0.05\left(^{*}\right)$.

result of reduced mRNA abundance and directly suppressed translation. Several hypotheses have been proposed to delineate how microRNAs suppress gene expression (Omer et al. 2009, Huntzinger \& Izaurralde 2011). In mammalian cells, it has been reported that the reduction in message RNA abundance results from accelerated deadenylation, which leads to rapid mRNA decay (Wu et al. 2006, 2010, Omer et al. 2009, Ricci et al. 2011). More recently, the direct repression of Aplp2 mRNA's translation by miR-153 has also been showed (Liang et al. 2011). Although the mechanism underlying the decrease in PCNA protein abundance caused by miR-376a remained unknown, our results indicated that
miR-376a is able to suppress Pcna expression by directly binding to the $3^{\prime}$ UTR of its mRNAs.

The role of microRNAs during primordial follicle assembly is poorly understood and previous studies on microRNAs in the developing ovaries were largely limited to assessing their expression profiles. For example, a total of 398 known microRNAs and 30 novel microRNAs were found to be expressed in the newborn mouse ovary; however, the exact role of any of them in follicular development is unknown (Ahn et al. 2010). Here, we found that mouse fetal ovaries transfected with miR-376a exhibited more primordial follicles than the controls (Fig. 3B) and similar results were observed in ovaries transfected with Pcna siRNAs (Fig. 3A and B). Furthermore, co-transfection of miR-376a mimics and PCna siRNAs did not further increase primordial follicles in ovaries (Fig. 3A and B). These results strongly indicate that miR-376a and Pcna siRNAs function in the same pathway to regulate primordial follicle formation. However, the transfection of miR-376a inhibitors had no obvious effect on primordial follicle assembly (Supplementary Fig. 3). This could be related to the low background concentration of miR-376a in the ovary. Therefore, the present observations demonstrate that miR-376a regulates primordial follicle assembly through regulating PCna expression. This is the first microRNA-target mRNA pairs that clearly demonstrated to regulate mammalian primordial follicle assembly.

In female mammals, germ cell loss is a crucial event during primordial follicle assembly. In fetal and neonatal mouse ovaries, approximately two thirds of oocytes underwent cell death and only the surviving ones developed into primordial follicles (Pepling \& Spradling 2001, Pepling 2006). Apoptosis has been proposed to be the major mechanism responsible for oocyte loss. Several genes, e.g. the $B C l 2$ family genes ( $B C l 2$ and $B a x)$ and Caspases (Casp2 and Casp4) have been reported to be involved in the regulation of oocyte apoptosis (Ratts et al. 1995, Bergeron et al. 1998, Rucker et al. 2000, Flaws et al. 2001, Morita et al. 2001). Our previous studies have also demonstrated that $P_{C n a}$ contribute actively to oocyte loss by regulating apoptosis during primordial follicle assembly in mouse ovaries ( $\mathrm{Xu}$ et al. 2011a). The expression of miR-376a in mouse ovaries, decreasing from $16.5 \mathrm{dpc}$ to $3 \mathrm{dpp}$ (Fig. 1A) indicates that this microRNA may be involved in oocyte loss through targeting Pcna during primordial follicle assembly. Moreover, microRNA ISH experiments demonstrated that miR-376a was localized in cytoplasm of some oocytes in cysts in $16.5 \mathrm{dpc}$ ovaries in which primordial follicle formation has not occurred yet and in cytoplasm of oocytes and some granulosa cells of primordial follicles in $1 \mathrm{dpp}$ ovaries (Fig. 1C). This different localization of miR-376a before and after primordial follicle assembly indicated that only the miR-376a-PCna pairs present in oocytes is involved in the assembly of primordial follicles. Indeed, in cultured mouse ovaries, we found that 
miR-376a transfection reduced oocyte apoptosis (Fig. 4A and $\mathrm{B}$ ). This is consistent with the increased expression of anti-apoptotic genes and suppression of pro-apoptotic genes (Fig. 4C). Among the apoptosis-associated genes, Casp3 expression was unchanged. This is consistent with former reports that oocyte death, initiated as a result of either developmental cues or pathological insults, was unaffected by the absence of Casp3 (Matikainen et al. 2001). However, Casp7, a pro-apoptotic gene, increased after miR-376a transfection, suggesting a more complicated mechanism of oocyte apoptosis than anticipated. During primordial follicle pool foundation, the prosurvival genes, Pard6a and $L h \times 8$, contribute to the maintenance of oocytes arrested at the diplotene stage (Choi et al. 2008, Wen et al. 2009). Increased expression of these oocyte pro-survival genes after miR-376a transfection is consistent with more surviving oocytes. Furthermore, as the culture time increased, there are still more primordial follicles in the miR-376a mimictransfected ovaries, while the difference in the developing follicle index between experimental and control ovaries decreased, which rules out the possibility that the increased number of primordial follicles after miR-376a mimics transfection are resulted from the postponing oocyte apoptosis. Additionally, the lack of an additive effect on oocyte loss in fetal mouse ovaries after co-transfection of miR-376a mimics with Pcna siRNAs (Fig. 4A and B) indicated that miR-376a and Pcna function in the same pathway, and functionally confirmed that miR376 a reduced oocyte apoptosis through targeting Pcna.

In studies using cultured cells, some microRNAs involved in the regulation of apoptosis have been reported. For example, the miR-34a, b, c, and miR-214 were observed to promote apoptosis by increasing the expression of Caspases, P21, P53, and Bax (Corney et al. 2007, Gammell 2007, Zenz et al. 2009). miR-210 and miR-155 repressed apoptosis by decreasing the expression of pro-apoptotic Caspases (Wang \& Lee 2009). However, all these data are obtained from experiments using cultured somatic cells. Our observations provide the first evidence for the existence of a new mechanism by which an individual microRNA regulates oocyte apoptosis in perinatal mouse ovaries.

In summary, we found that miR-376a functions as a negative regulator of $P$ Cna by binding to PCna mRNA $3^{\prime}$ UTR. Overexpression of miR-376a increased primordial follicle assembly by reducing oocyte apoptosis mediated by the downregulation of Pcna in perinatal mouse ovaries. To our knowledge, this is the first microRNAtarget mRNA pairs that functions during folliculogenesis in mammalian ovaries and further our understanding of the regulation of primordial follicle assembly.

\section{Supplementary data}

This is linked to the online version of the paper at http://dx.doi. org/10.1530/REP-13-0508.

\section{Declaration of interest}

The authors declare that there is no conflict of interest that could be perceived as prejudicing the impartiality of the research reported.

\section{Funding}

This work was supported by the National Basic Research Program (2013CB947900, 2012CB944402, 2011CB944501, and 2013CB945502) of China (973) and the Knowledge Innovation Program of the Chinese Academy of Sciences (KSCX2-EW-R-07). The funders had no role in study design, data collection and analysis, decision to publish, or preparation of the manuscript.

\section{Author contribution statement}

$\mathrm{H}$ Zhang, $\mathrm{X}$ Jiang, and $\mathrm{Q}$ Shi conceived and designed the experiments. $H$ Zhang, $X$ Jiang, $T$ Ma, W Zheng, and $R$ Sun performed the experiments. H Zhang, X Jiang, Y Zhang, J Hua, and $B$ Xu analyzed the data. $\mathrm{H}$ Zhang, X Jiang, and Q Shi wrote the paper. W Shen, H J Cooke, J Qiao and Q Hao modified the manuscript.

\section{Acknowledgements}

The authors thank Dr Toshiaki Noce (Mitsubishi Kagaku of life Sciences, Tokyo, Japan) for kindly providing us with antibodies against MVH. They also thank Dr Cheng Wang (University of Nebraska Medical Center, Nebraska, USA) for his suggestions on ovary culture and RNAi experiments.

\section{References}

Ahn HW, Morin RD, Zhao H, Harris RA, Coarfa C, Chen ZJ, Milosavljevic A, Marra MA \& Rajkovic A 2010 MicroRNA transcriptome in the newborn mouse ovaries determined by massive parallel sequencing. Molecular Human Repoduction 16 463-471. (doi:10.1093/molehr/gaq017)

Baker TG 1963 A quantitative and cytological study of germ cells in human ovaries. Proceedings of the Royal Society of London. Series B, Biological Sciences 158 417-433. (doi:10.1098/rspb.1963.0055)

Baley J \& Li J 2012 MicroRNAs and ovarian function. Journal of Ovarian Research 5 8. (doi:10.1186/1757-2215-5-8)

Balla M, Angelopoulou R, Lavranos G \& Kittas C 2008 Follicular cells versus oocytes: cell population dynamics in the developing ovary. Tissue \& Cell 40 373-381. (doi:10.1016/j.tice.2008.03.006)

Bartel DP 2009 MicroRNAs: target recognition and regulatory functions. Cell 136 215-233. (doi:10.1016/j.cell.2009.01.002)

Bergeron L, Perez GI, Macdonald G, Shi L, Sun Y, Jurisicova A, Varmuza S, Latham KE, Flaws JA, Salter JC et al. 1998 Defects in regulation of apoptosis in caspase-2-deficient mice. Genes and Development 12 1304-1314. (doi:10.1101/gad.12.9.1304)

Betel D, Wilson M, Gabow A, Marks DS \& Sander C 2008 The microRNA.org resource: targets and expression. Nucleic Acids Research 36 D149-D153. (doi:10.1093/nar/gkm995)

Borum K 1961 Oogenesis in the mouse. A study of the meiotic prophase. Experimental Cell Research 24 495-507. (doi:10.1016/0014-4827(61) 90449-9)

Broekmans FJ, Knauff EA, te Velde ER, Macklon NS \& Fauser BC 2007 Female reproductive ageing: current knowledge and future trends. Trends in Endocrinology and Metabolism 18 58-65. (doi:10.1016/j.tem.2007. 01.004) 
Carletti MZ, Fiedler SD \& Christenson LK 2010 MicroRNA 21 blocks apoptosis in mouse periovulatory granulosa cells. Biology of Reproduction 83 286-295. (doi:10.1095/biolreprod.109.081448)

Chang CD, Ottavio L, Travali S, Lipson KE \& Baserga R 1990 Transcriptional and posttranscriptional regulation of the proliferating cell nuclear antigen gene. Molecular and Cellular Biology 10 3289-3296.

Chen Y, Jefferson WN, Newbold RR, Padilla-Banks E \& Pepling ME 2007 Estradiol, progesterone, and genistein inhibit oocyte nest breakdown and primordial follicle assembly in the neonatal mouse ovary in vitro and in vivo. Endocrinology 148 3580-3590. (doi:10.1210/en.2007-0088)

Choi Y, Qin Y, Berger MF, Ballow DJ, Bulyk ML \& Rajkovic A 2007 Microarray analyses of newborn mouse ovaries lacking Nobox. Biology of Reproduction 77 312-319. (doi:10.1095/biolreprod.107.060459)

Choi Y, Ballow DJ, Xin Y \& Rajkovic A 2008 Lim homeobox gene, lhx8, is essential for mouse oocyte differentiation and survival. Biology of Reproduction 79 442-449. (doi:10.1095/biolreprod.108.069393)

Corney DC, Flesken-Nikitin A, Godwin AK, Wang W \& Nikitin AY 2007 MicroRNA-34b and microRNA-34c are targets of p53 and cooperate in control of cell proliferation and adhesion-independent growth. Cancer Research 67 8433-8438. (doi:10.1158/0008-5472.CAN-07-1585)

Coucouvanis EC, Sherwood SW, Carswell-Crumpton C, Spack EG \& Jones PP 1993 Evidence that the mechanism of prenatal germ cell death in the mouse is apoptosis. Experimental Cell Research 209 238-247. (doi:10.1006/excr.1993.1307)

De Felici M, Lobascio AM \& Klinger FG 2008 Cell death in fetal oocytes: many players for multiple pathways. Autophagy 4 240-242.

De Pol A, Vaccina F, Forabosco A, Cavazzuti E \& Marzona L 1997 Apoptosis of germ cells during human prenatal oogenesis. Human Reproduction 12 2235-2241. (doi:10.1093/humrep/12.10.2235)

Essers J, Theil AF, Baldeyron C, van Cappellen WA, Houtsmuller AB, Kanaar R \& Vermeulen W 2005 Nuclear dynamics of PCNA in DNA replication and repair. Molecular and Cellular Biology 25 9350-9359. (doi:10.1128/MCB.25.21.9350-9359.2005)

Faddy MJ \& Gosden RG 1996 A model conforming the decline in follicle numbers to the age of menopause in women. Human Reproduction 11 1484-1486. (doi:10.1093/oxfordjournals.humrep.a019422)

Faddy MJ, Gosden RG, Gougeon A, Richardson SJ \& Nelson JF 1992 Accelerated disappearance of ovarian follicles in mid-life: implications for forecasting menopause. Human Reproduction 7 1342-1346.

Flaws JA, Hirshfield AN, Hewitt JA, Babus JK \& Furth PA 2001 Effect of $\mathrm{bcl}-2$ on the primordial follicle endowment in the mouse ovary. Biology of Reproduction 64 1153-1159. (doi:10.1095/biolreprod64. 4.1153)

Fujiwara Y, Komiya T, Kawabata H, Sato M, Fujimoto H, Furusawa M \& Noce T 1994 Isolation of a DEAD-family protein gene that encodes a murine homolog of Drosophila vasa and its specific expression in germ cell lineage. PNAS 91 12258-12262. (doi:10.1073/pnas.91.25.12258)

Gammell P 2007 MicroRNAs: recently discovered key regulators of proliferation and apoptosis in animal cells: identification of miRNAs regulating growth and survival. Cytotechnology 53 55-63. (doi:10.1007/ s10616-007-9049-4)

Grentzmann G, Ingram JA, Kelly PJ, Gesteland RF \& Atkins JF 1998 A dual-luciferase reporter system for studying recoding signals. RNA 4 479-486. (doi:10.1017/S1355838298971576)

Han L, Zhang A, Zhou X, Xu P, Wang GX, Pu PY \& Kang CS 2010 Downregulation of Dicer enhances tumor cell proliferation and invasion. International Journal of Oncology 37 299-305. (doi:10.3892/ljo_ 00000678)

Higuchi R, Krummel B \& Saiki RK 1988 A general method of in vitro preparation and specific mutagenesis of DNA fragments: study of protein and DNA interactions. Nucleic Acids Research 16 7351-7367. (doi:10.1093/nar/16.15.7351)

Huang J, Ju Z, Li Q, Hou Q, Wang C, Li J, Li R, Wang L, Sun T, Hang S et al. 2011 Solexa sequencing of novel and differentially expressed microRNAs in testicular and ovarian tissues in Holstein cattle. International Journal of Biological Sciences 7 1016-1026. (doi:10.7150/ijbs.7.1016)

Huntzinger E \& Izaurralde E 2011 Gene silencing by microRNAs: contributions of translational repression and mRNA decay. Nature Reviews. Genetics 12 99-110. (doi:10.1038/nrg2936)

Hutt KJ, McLaughlin EA \& Holland MK 2006 Primordial follicle activation and follicular development in the juvenile rabbit ovary. Cell and Tissue Research 326 809-822. (doi:10.1007/s00441-006-0223-3)
Johnson J, Canning J, Kaneko T, Pru JK \& Tilly JL 2004 Germline stem cells and follicular renewal in the postnatal mammalian ovary. Nature $\mathbf{4 2 8}$ 145-150. (doi:10.1038/nature02316)

Kerr JB, Duckett R, Myers M, Britt KL, Mladenovska T \& Findlay JK 2006 Quantification of healthy follicles in the neonatal and adult mouse ovary: evidence for maintenance of primordial follicle supply. Reproduction 132 95-109. (doi:10.1530/rep.1.01128)

Kim SY, Cordeiro MH, Serna VA, Ebbert K, Butler LM, Sinha S, Mills AA, Woodruff TK \& Kurita T 2013 Rescue of platinum-damaged oocytes from programmed cell death through inactivation of the p53 family signaling network. Cell Death and Differentiation 20 987-997. (doi:10.1038/cdd. 2013.31)

Korfsmeier KH 2002 PCNA in the ovary of zebrafish (Brachydanio rerio, Ham.-Buch.). Acta Histochemica 104 73-76. (doi:10.1078/0065-128100632)

Krol J, Loedige I \& Filipowicz W 2010 The widespread regulation of microRNA biogenesis, function and decay. Nature Reviews. Genetics 11 597-610. (doi:10.1038/Nrg2843)

Lei L, Jin S, Gonzalez G, Behringer RR \& Woodruff TK 2010 The regulatory role of Dicer in folliculogenesis in mice. Molecular and Cellular Endocrinology 315 63-73. (doi:10.1016/j.mce.2009.09.021)

Liang C, Zhu H, Xu Y, Huang L, Ma C, Deng W, Liu Y \& Qin C 2011 MicroRNA-153 negatively regulates the expression of amyloid precursor protein and amyloid precursor-like protein 2. Brain Research 1455 103-113. (doi:10.1016/j.brainres.2011.10.051)

Lobascio AM, Klinger FG, Scaldaferri ML, Farini D \& De Felici M 2007 Analysis of programmed cell death in mouse fetal oocytes. Reproduction 134 241-252. (doi:10.1530/REP-07-0141)

Maheshwari A \& Fowler PA 2008 Primordial follicular assembly in humans - revisited. Zygote 16 285-296. (doi:10.1017/S0967199408004802)

Matikainen T, Perez GI, Zheng TS, Kluzak TR, Rueda BR, Flavell RA \& Tilly JL 2001 Caspase-3 gene knockout defines cell lineage specificity for programmed cell death signaling in the ovary. Endocrinology 142 2468-2480. (doi:10.1210/en.142.6.2468)

Meredith S, Dudenhoeffer G \& Jackson K 2000 Classification of small type $\mathrm{B} / \mathrm{C}$ follicles as primordial follicles in mature rats. Journal of Reproduction and Fertility 119 43-48. (doi:10.1530/reprod/119.1.43)

Morita Y, Maravei DV, Bergeron L, Wang S, Perez GI, Tsutsumi O, Taketani Y, Asano M, Horai R, Korsmeyer SJ et al. 2001 Caspase-2 deficiency prevents programmed germ cell death resulting from cytokine insufficiency but not meiotic defects caused by loss of ataxia telangiectasia-mutated (Atm) gene function. Cell Death and Differentiation 8 614-620. (doi:10.1038/sj.cdd.4400845)

Murchison EP, Stein P, Xuan Z, Pan H, Zhang MQ, Schultz RM \& Hannon GJ 2007 Critical roles for Dicer in the female germline. Genes and Development 21 682-693. (doi:10.1101/gad.1521307)

Muskhelishvili L, Wingard SK \& Latendresse JR 2005 Proliferating cell nuclear antigen - a marker for ovarian follicle counts. Toxicologic Pathology 33 365-368. (doi:10.1080/01926230590930164)

Nilsson E, Rogers N \& Skinner MK 2007 Actions of anti-Mullerian hormone on the ovarian transcriptome to inhibit primordial to primary follicle transition. Reproduction 134 209-221. (doi:10.1530/REP-07-0119)

Oktay K, Schenken RS \& Nelson JF 1995 Proliferating cell nuclear antigen marks the initiation of follicular growth in the rat. Biology of Reproduction 53 295-301. (doi:10.1095/biolreprod53.2.295)

Omer AD, Janas MM \& Novina CD 2009 The chicken or the egg: microRNA-mediated regulation of mRNA translation or mRNA stability. Molecular Cell 35 739-740. (doi:10.1016/j.molcel.2009.09.003)

Otsuka M, Zheng M, Hayashi M, Lee JD, Yoshino O, Lin S \& Han J 2008 Impaired microRNA processing causes corpus luteum insufficiency and infertility in mice. Journal of Clinical Investigation 118 1944-1954. (doi:10.1172/JCl33680)

Paddison PJ, Silva JM, Conklin DS, Schlabach M, Li M, Aruleba S, Balija V, O'Shaughnessy A, Gnoj L, Scobie K et al. 2004 A resource for large-scale RNA-interference-based screens in mammals. Nature 428 427-431. (doi:10.1038/nature02370)

Pepling ME 2006 From primordial germ cell to primordial follicle: mammalian female germ cell development. Genesis 44 622-632. (doi:10.1002/dvg.20258)

Pepling ME \& Spradling AC 2001 Mouse ovarian germ cell cysts undergo programmed breakdown to form primordial follicles. Developmental Biology 234 339-351. (doi:10.1006/dbio.2001.0269) 
Pesce M \& De Felici M 1994 Apoptosis in mouse primordial germ cells: a study by transmission and scanning electron microscope. Anatomy and Embryology 189 435-440. (doi:10.1007/BF00185438)

Picut CA, Swanson CL, Scully KL, Roseman VC, Parker RF \& Remick AK 2008 Ovarian follicle counts using proliferating cell nuclear antigen (PCNA) and semi-automated image analysis in rats. Toxicologic Pathology 36 674-679. (doi:10.1177/0192623308317428)

Raschzok N, Werner W, Sallmon H, Billecke N, Dame C, Neuhaus P \& Sauer IM 2011 Temporal expression profiles indicate a primary function for microRNA during the peak of DNA replication after rat partial hepatectomy. American Journal of Physiology. Regulatory, Integrative and Comparative Physiology 300 R1363-R1372. (doi:10.1152/ajpregu. 00632.2010)

Ratts VS, Flaws JA, Kolp R, Sorenson CM \& Tilly JL 1995 Ablation of bcl-2 gene expression decreases the numbers of oocytes and primordial follicles established in the post-natal female mouse gonad. Endocrinology 136 3665-3668. (doi:10.1210/endo.136.8.7628407)

Reddy P, Liu L, Adhikari D, Jagarlamudi K, Rajareddy S, Shen Y, Du C, Tang W, Hamalainen T, Peng SL et al. 2008 Oocyte-specific deletion of Pten causes premature activation of the primordial follicle pool. Science 319 611-613. (doi:10.1126/science.1152257)

Ricci EP, Limousin T, Soto-Rifo R, Allison R, Poyry T, Decimo D, Jackson RJ \& Ohlmann T 2011 Activation of a microRNA response in trans reveals a new role for poly $(\mathrm{A})$ in translational repression. Nucleic Acids Research 39 5215-5231. (doi:10.1093/nar/gkr086)

Ro S, Song R, Park C, Zheng H, Sanders KM \& Yan W 2007 Cloning and expression profiling of small RNAs expressed in the mouse ovary. RNA 13 2366-2380. (doi:10.1261/rna.754207)

Robker RL \& Richards JS 1998 Hormone-induced proliferation and differentiation of granulosa cells: a coordinated balance of the cell cycle regulators cyclin D2 and p27Kip1. Molecular Endocrinology 12 924-940. (doi:10.1210/mend.12.7.0138)

Rodrigues P, Limback D, McGinnis LK, Plancha CE \& Albertini DF 2009 Multiple mechanisms of germ cell loss in the perinatal mouse ovary. Reproduction 137 709-720. (doi:10.1530/REP-08-0203)

Rucker EB III, Dierisseau P, Wagner KU, Garrett L, Wynshaw-Boris A, Flaws JA \& Hennighausen L $2000 \mathrm{BCl}-\mathrm{x}$ and Bax regulate mouse primordial germ cell survival and apoptosis during embryogenesis. Molecular Endocrinology 14 1038-1052. (doi:10.1210/mend.14.7.0465)

Shen W, Li L, Bai Z, Pan Q, Ding M \& Deng H 2007 In vitro development of mouse fetal germ cells into mature oocytes. Reproduction 134 223-231. (doi:10.1530/REP-06-0378)

Sirotkin AV, Laukova M, Ovcharenko D, Brenaut P \& Mlyncek M 2010 Identification of microRNAs controlling human ovarian cell proliferation and apoptosis. Journal of Cellular Physiology 223 49-56. (doi:10.1002/ jcp.21999)

Sullivan SD \& Castrillon DH 2011 Insights into primary ovarian insufficiency through genetically engineered mouse models. Seminars in Reproductive Medicine 29 283-298. (doi:10.1055/s-0031-1280914)

Torley KJ, da Silveira JC, Smith P, Anthony RV, Veeramachaneni DN, Winger QA \& Bouma GJ 2011 Expression of miRNAs in ovine fetal gonads: potential role in gonadal differentiation. Reproductive Biology and Endocrinology 9 2. (doi:10.1186/1477-7827-9-2)
Tripurani SK, Xiao C, Salem M \& Yao J 2010 Cloning and analysis of fetal ovary microRNAs in cattle. Animal Reproduction Science 120 16-22. (doi:10.1016/j.anireprosci.2010.03.001)

Wang C \& Roy SK 2006 Expression of growth differentiation factor 9 in the oocytes is essential for the development of primordial follicles in the hamster ovary. Endocrinology 147 1725-1734. (doi:10.1210/en.20051208)

Wang Y \& Lee CG 2009 MicroRNA and cancer - focus on apoptosis. Journal of Cellular and Molecular Medicine 13 12-23. (doi:10.1111/ j.1582-4934.2008.00510.x)

Wen J, Zhang H, Li G, Mao G, Chen X, Wang J, Guo M, Mu X, Ouyang H, Zhang $\mathbf{M}$ et al. 2009 PAR6, a potential marker for the germ cells selected to form primordial follicles in mouse ovary. PLOS ONE 4 e7372. (doi:10. 1371/journal.pone.0007372)

Wu L, Fan J \& Belasco JG 2006 MicroRNAs direct rapid deadenylation of mRNA. PNAS 103 4034-4039. (doi:10.1073/pnas.0510928103)

Wu E, Thivierge C, Flamand M, Mathonnet G, Vashisht AA, Wohlschlegel J, Fabian MR, Sonenberg N \& Duchaine TF 2010 Pervasive and cooperative deadenylation of $3^{\prime}$ UTRs by embryonic microRNA families. Molecular Cell 40 558-570. (doi:10.1016/j.molcel.2010.11.003)

Xu B, Hua J, Zhang Y, Jiang X, Zhang H, Ma T, Zheng W, Sun R, Shen W, Sha J et al. 2011 a Proliferating cell nuclear antigen (PCNA) regulates primordial follicle assembly by promoting apoptosis of oocytes in fetal and neonatal mouse ovaries. PLOS ONE 6 e16046. (doi:10.1371/journal. pone.0016046)

Xu S, Linher-Melville K, Yang BB, Wu D \& Li J 2011 b Micro-RNA378 (miR378) regulates ovarian estradiol production by targeting aromatase. Endocrinology 152 3941-3951. (doi:10.1210/en.2011-1147)

Zenz T, Mohr J, Eldering E, Kater AP, Buhler A, Kienle D, Winkler D, Durig J, van Oers MH, Mertens D et al. 2009 miR-34a as part of the resistance network in chronic lymphocytic leukemia. Blood 113 3801-3808. (doi:10.1182/blood-2008-08-172254)

Zhang Z, Shen B, Wang Y, Chen Y, Wang G, Lin P \& Zou Z 2010 Molecular cloning of proliferating cell nuclear antigen and its differential expression analysis in the developing ovary and testis of penaeid shrimp Marsupenaeus japonicus. DNA and Cell Biology 29 163-170. (doi:10. 1089/dna.2009.0958)

Zhang Y, Yang Y, Zhang H, Jiang X, Xu B, Xue Y, Cao Y, Zhai Q, Zhai Y, Xu M et al. 2011 Prediction of novel pre-microRNAs with high accuracy through boosting and SVM. Bioinformatics 27 1436-1437. (doi:10.1093/ bioinformatics/btr148)

Zhang J, Ji X, Zhou D, Li Y, Lin J, Liu J, Luo H \& Cui S 2013 miR-143 is critical for the formation of primordial follicles in mice. Frontiers in Bioscience 18 588-597. (doi:10.2741/4122)

Received 7 October 2013

First decision 28 November 2013

Revised manuscript received 22 March 2014

Accepted 31 March 2014 